\title{
Design de Serviços e Experiência do Usuário (UX): uma análise do relacionamento das áreas
}

\section{Service Design And User Experience (UX): $a$ analysis on the areas relationship}

\author{
Mayara Ramos ${ }^{1}$ \\ Eugenio Andrés Díaz Merino ${ }^{2}$ \\ Giselle Schmidt Alves Díaz Merino ${ }^{3}$ \\ Marcelo Gitirana Gomes Ferreira ${ }^{4}$
}




\section{Resumo}

As empresas, atualmente, estão preocupadas em desenvolver e entregar valor para os clientes. O Design de Serviços tem se tornado uma vantagem competitiva, ao buscar entregar experiências de serviço que atendam as necessidades clientes. A Experiência do Usuário por sua vez aborda a incorporação do feedback usuários no desenvolvimento de serviços/produtos com a finalidade de atender às necessidades dos usuários e que tenham alta usabilidade. O uso conjunto dessas disciplinas pode aprimorar o fornecimento de valor. Esse artigo tem por objetivo analisar uma metodologia utilizada no Design de Serviços e ferramentas aplicadas no processo de desenvolvimento, identificando se há interseção e como ela se relaciona com a abordagem da Experiência do Usuário e suas medidas. Acredita-se que com o uso do Design de Serviços e Experiência do Usuário os resultados trarão maior chances da entrega do valor desejado pelos clientes, criar relacionamento com os clientes, maior participação no mercado, valor de marca.

Palavras-Chave: Design de Serviço; Experiência do Usuário (UX); Desenvolvimento de serviços.

\section{Abstract}

Companies, now a days, are concerned in developing and delivering value to the clients. Service Design is becoming a significant competitive advantage, once it seeks to deliver service experiences that fulfill clients necessities. User Experience addresses the users feedback incorporation on the development of services/products in order to accomplish the users needs and with high usability. The combined use of these disciplines may improve the value delivery. This article aims to analyze a methodology used on Service Design and tools applied on the process of development, in order to identify if there is a intersection and how it relates with the User Experience approach and its measures. It is believed that with use of Service Design and User Experience the results have a better chance on delivering the value desired by the clients, building customer relationship, higher market share and brand value.

Keywords: Service Design; User Experience (UX); Service Development.

ISSN: $1808-3129$

Universidade Federal de Santa Catarina - UFSC/PPGEP (Programa de Pós-Graduação em Engenharia de Produção) - Brasil mayara.ramos@gmail.com Eugenio Andrés Díaz Merino - UFSC/PPGEP/POSDESIGN - Brasil eugenio.merino@ufsc.br Giselle Schmidt Alves Díaz Merino - UFSC/POSDESIGN - Brasil gisellemerino@gmail.com Marcelo Gitirana Gomes Ferreira - UDESC/PPGDesign - Brasil marcelo.gitirana@gmail.com 


\section{Introdução}

A investigação sobre as atividades de prestação de serviços vem crescendo nas últimas décadas. $\mathrm{O}$ avanço dessas atividades em relação à capacidade de geração de empregos vem motivando a elaboração de novos estudos a respeito do setor (IBGE, 2013).

A Pesquisa Anual de Serviços (PAS) do IBGE, para o ano de 2011, apresentou um total de 1.081 .012 empresas atuando na área de serviços no país (IBGE, 2013). No período de 2003 a 2013, a faixa de participação ocupada pelos Serviços no Produto Interno Bruto (PIB) subiu 4,6 pontos porcentuais, de $64,8 \%$ para $69,4 \%$ do PIB (FERREIRA, 2014).

Os processos produtivos e a atividade econômica têm se tornado mais complexas, fazendo com que os serviços não sejam mais analisados como um todo homogêneo. Identifica-se a alteração qualitativa das cestas de consumo das famílias com o aumento da participação dos serviços, assim como o desenvolvimento de novas atividades e produtos que retratam mudanças na demanda. Estas alterações desempenham um papel determinante no desenvolvimento dos serviços nas últimas décadas tanto por meio do aumento da terceirização quanto pela absorção de tecnologias pelos serviços (IBGE, 2013). A natureza da economia dos serviços também está passando por uma transformação, indo de uma natureza baseada em transações para relações baseadas na experiência (FITZSIMMONS, FITZSIMMONS, 2005).

Moritz (2005) afirma que estamos cercados por serviços todos os dias - entrega de correspondências, empréstimo de livros na biblioteca, etc. Os serviços estão presentes a séculos, os antigos gregos e romanos tinham servos e ainda antes disso, serviços eram prestados e pagos. Algumas coisas mudaram drasticamente nos últimos 25 anos, assim como a revolução industrial transformou a sociedade e a economia, estamos passando pela revolução dos serviços.

Para o autor os quatro maiores direcionadores para a revolução dos serviços são:

- a economia dos serviços está crescendo - essa economia é a parte dominante da maioria dos países desenvolvidos;

- o mercado de produtos está satisfeito - os produtos têm ficado cada vez mais similares, tanto em questões de forma quanto satisfação;

- a tecnologia possibilita serviços - novas tecnologias servem como facilitadores de novos serviços, e possibilita que serviços sejam prestados de novas maneiras, a tecnologia representa novas possibilidades e desafios;

- pessoas tem necessidades individuais - as necessidades não podem ser padronizadas, dependendo do contexto e situação as necessidades de cada cliente pode ser diferente, mesmo em um mesmo serviço.

As oportunidades do Design de Serviço estão em se conduzir a esses direcionadores e dar suporte ao serviço de mercado com novos conceitos. Organizações de sucesso mudaram de uma organização centrada em produtos para oferecer principalmente serviços, outras organizações também podem se beneficiar com tal mudança. As organizações precisam encontrar novas maneiras de se destacar dos con- 
correntes e oferecer novos valores. Design de Serviços pode auxiliar a criar novos relacionamentos entre organizações e clientes (MORITZ, 2005).

Polaine, Lovlie e Reason (2013) afirmam que o Design de Serviços está se tornando uma vantagem competitiva chave. Elementos físicos e tecnologias podem ser facilmente copiados, mas as experiências de serviço estão enraizadas na cultura corporativa e são muito mais difíceis de replicar. As pessoas escolhem usar serviços que sentem lhes dar a melhor experiência pelo seu dinheiro. Serviços tratam da interação entre pessoas, e suas motivações e comportamentos. A experiência do serviço é feita das interações dos consumidores com os vários pontos de contato (touchpoints), e a qualidade do serviço pode ser definida por quão bem os pontos de contato trabalham em conjunto com o consumidor.

Norman (1998) coloca que o novo papel das empresas é organizar a criação de valor, na perspectiva de considerar os clientes não como o fim do processo de produção, mas como coprodutores de valor. Segundo Morelli (2009) este posicionamento amplia os interesses das empresas além dos seus limites físicos e formais da coprodução de valor. Neste cenário as empresas devem atuar como organizadoras e facilitadores entre os outros atores envolvidos, incluindo prestadores de serviços e instituições locais e os consumidores.

Experiência do Usuário de alta qualidade se tornou um fator competitivo central do desenvolvimento de produto/serviço de mercados consumidores maduros (OBRIST, ROTO, VÄÄNÄNEN-VAINIO-MATTILA, 2009).

De encontro com o exposto pelos autores citados e o novo papel das empresas, pode-se dizer que o fornecimento de valor e o relacionamento com os consumidores pode ser aprimorado ou atingido pelo uso da experiência do usuário (UX) em conjunto com o design de serviços.

A ISO 9241-11:2010 define a Experiência do Usuário como percepções e respostas das pessoas resultantes do uso de um produto, sistema ou serviço. A experiência do usuário inclui todas as emoções, crenças, preferências, percepções, respostas físicas e psicológicas, comportamentos e realizações do usuário que ocorrem antes, durante e depois do uso (ABNT, 2011). A UXPA (User Experience Professionals Association - Associação dos Profissionais de Experiência do Usuário), coloca a UX ${ }^{1}$ como uma abordagem ao desenvolvimento de produtos/serviços que incorpora o feedba$c k$ direto dos usuários durante todo ciclo de desenvolvimento (design centrado no usuário). A finalidade desta abordagem é reduzir custos e criar produtos/serviços e ferramentas que atendam às necessidades dos usuários e tenham alta usabilidade (UXPA, 2014).

Nesse artigo foi analisado uma metodologia de Design de serviços (Duplo Diamante) e ferramentas aplicadas nessa metodologia, identificando se existe uma interseção com a abordagem da Experiência do Usuário (UX) e suas medidas. Caso não sejam identificadas interseções, pretende-se analisar como a UX pode se relacionar com a metodologia de Design de Serviços.

Acredita-se que com o uso do Design de Serviços e UX de forma conjunta pode entregar resultados com maiores chances da entrega do valor desejado pelos clien-

${ }^{1}$ Sigla adotada nos estudos internacionais de Experiência do Usuário - do inglês User Experience (UX). 
tes, criando um relacionamento e a fidelização dos clientes levando a uma maior participação no mercado e a valorização da marca.

\section{Procedimentos metodológicos}

Essa pesquisa por ser cunho primariamente exploratório, foi realizado em duas etapas uma de levantamento de informações e uma segunda analítica. A primeira etapa consistiu numa revisão bibliográfica narrativa sobre Design de Serviços e Experiência do Usuário, segundo a classificação de Cordeiro (2007). A revisão abordou os conceitos, metodologias, ferramentas e mensurações dos temas Design de Serviço e UX.

Com a revisão dos conceitos, a segunda etapa, foi uma análise por meio de uma tabela comparativa, buscando identificar as similaridades e interseções dessas disciplinas e se/como podem ser aplicadas conjuntamente, isso visando a melhoria na entrega de valor e experiência desejada pelos usuários. A Figura 2.1 mostra o procedimento adotado nesse trabalho.

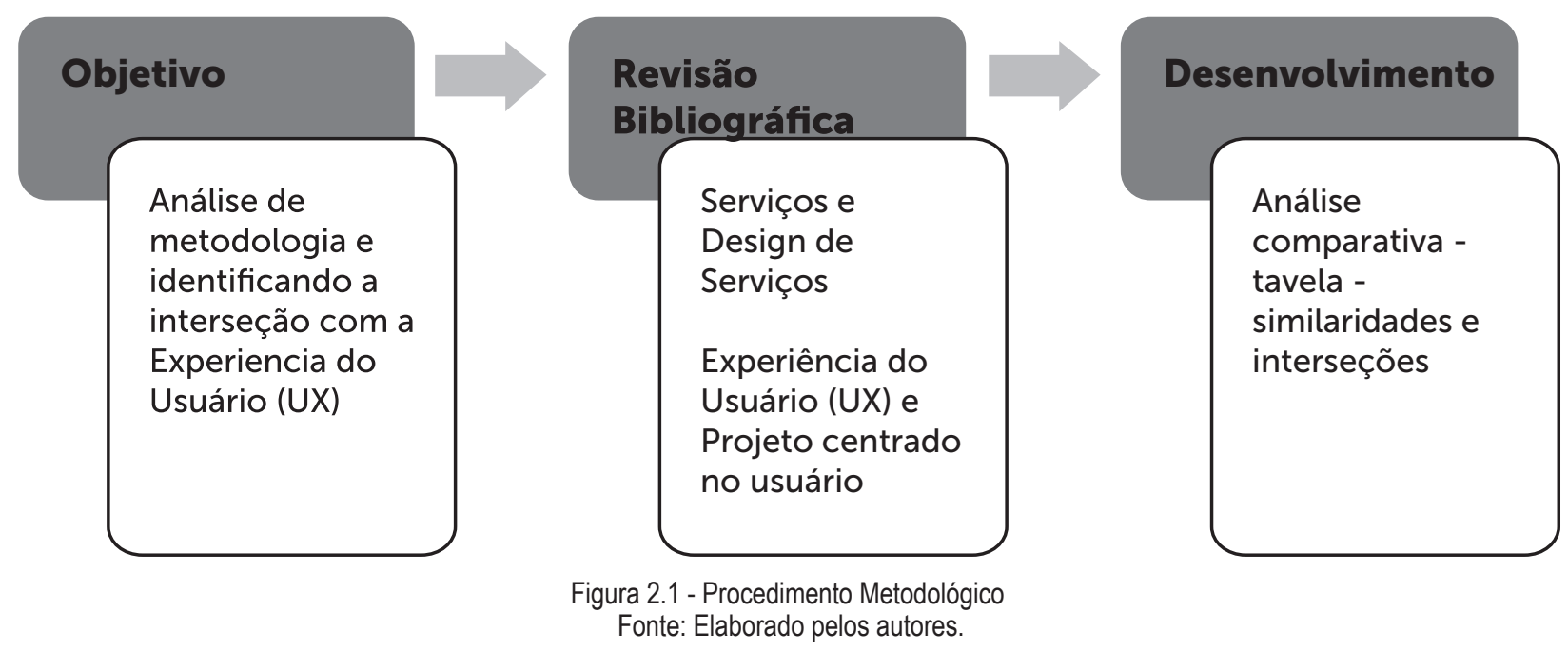

\section{Fundamentação teórica}

\section{Serviços}

Os serviços estão no centro da atividade econômica de qualquer sociedade. Os serviços são parte integrante da sociedade, estão presentes no cerne da economia e são fundamentais para que se mantenha sadia e funcional (FITZSIMMONS, FITZSIMMONS, 2005). Um serviço é um meio de entregar valor para o consumidor facilitando resultados que os consumidores querem atingir sem a propriedade de custos e riscos. Serviços facilitam resultados por aumentar o desempenho da tarefa associada e reduzindo o efeito das restrições. $O$ resultado é um aumento na probabilidade dos resultados desejados (RUDD; LLOYD, 2007).

Dentre as diversas definições de serviço encontradas, segundo Fitzsimmons e Fitzsimmons (2005), todas apresentam em comum a ideia de intangibilidade e consumo simultâneo. Morelli (2009) indica as três principais características dos serviços: 
são intangíveis; tem uma relação direta entre fornecedor e consumidor; e os consumidores/usuários participam na produção do serviço. Moritz (2005), apresenta outras características do serviço além das apresentadas: não é possível separar o serviço do consumo; não podem ser armazenados; não podem ser possuídos; são experiências complexas; e é difícil mensurar sua qualidade.

A intangibilidade dos serviços implica que estes não existem antes do momento em que são produzidos e consumidos, sendo a produção e consumo simultâneos (MORELLI, 2009). Moritz (2005) no entanto define a intangibilidade dos serviços por não possuem forma física, não podem ser vistos antes de ser adquiridos ou leva-los para casa após a compra, não é possível pegá-los, porém, com frequência é possível ver os seus resultados; já a característica de não ser possível separar o serviço do consumo se adapta ao conceito de intangibilidade do serviço apresentada por Morelli.

As demais características apresentadas por Moritz (2005) são definidas como:

- Não são armazenáveis: os clientes esperam que os serviços estejam disponíveis na maior parte, ou todo o tempo. Serviços perdem seu valor se não são utilizados.

- Não podem ser possuídos: a maioria dos serviços são utilizados no momento. Não é possível transportá-los para casa. Serviços são usados invés de possuídos.

- Experiências complexas: serviços ocorrem no decorrer do tempo e através de diversos pontos de contato (touchpoints). Os clientes percebem os serviços em diferentes níveis. A interface global e experiência conectada é uma combinação das experiências de todos os pontos de contato.

- Mensuração qualidade: as medidas de qualidade tendem a ser qualitativas, e por isso apresentam grande variabilidade.

Ainda em relação as características, Han (2010) coloca que o serviço é uma plataforma que consiste de interações entre pessoas e objetos com as características: permitir que pessoas no sistema (stakeholders) interajam entre elas - direta ou indiretamente - afim de criar certos valores para eles mesmos ou para outros; um sistema facilitado por objetos tangíveis e mídias para permitir interações; informação e conhecimento são recursos fundamentais para a criação de valor; e experiências individuais como um "prosumer" (produtor + consumidor) que determinam o valor criado.

Um produto físico pode ser claramente descrito em termos dos seus atributos (se não suas funções). Um serviço não é tão facilmente especificado nem realmente demonstrado antes da compra. Uma maneira de conceber um serviço em oferta - benefícios oferecidos ao cliente em um sistema de serviços - é usar um produto físico como metáfora e listar mais claramente possível o que está sendo oferecido ou o que deve ser obtido como resultado da prestação do serviço (NORMANN, 1993). A Tabela 2.1 apresenta uma comparação das características de produto e serviço demonstrando suas diferenças.

Tabela 2.1 - Comparação entre as características de Produtos e Serviços

\begin{tabular}{ll}
\hline Produto & Serviço \\
\hline Produzido & Realizados \\
Material & Imaterial
\end{tabular}


Tangível

Pode ser estocado

Geralmente sem cliente

Consumido após o consumo

Defeitos em manufatura
Intangível

Não pode ser estocado

Interação com o cliente

Consumo $=$ produção

Erros no comportamento

Fonte: Traduzido pela autora de Moritz (2009, p. 30).

Serviço é a provisão de informação - ou uso de informação - para um consumidor que deseje, com ou sem acompanhamento de bens/ferramentas (HAN, 2010). Esses acompanhamentos podem ser caracterizados pelo pacote de serviços.

Um pacote de serviços é um conjunto de itens relacionados oferecidos ao cliente, as vezes um dos itens é claramente predominante. Por exemplo, em um serviço de transporte aéreo o transporte entre duas cidades é mais importante do que as condições de limpeza do aeroporto. Nesse caso pode-se distinguir um serviço-núcleo (transporte aéreo) e serviços periféricos ou secundários (condições do aeroporto) que fazem parte do pacote (NORMANN, 1993). Para Fitzsimmons e Fitzsimmons (2005) o pacote de serviços é definido como um conjunto de mercadorias e serviços que são fornecidos em um ambiente. Esse conjunto é composto por: instalações de apoio, bens facilitadores, informações, serviços explícitos e serviços implícitos.

A experiência e avaliação do cliente sobre o serviço total obtido são determinados por dois fatores: se o pacote de serviços inclui todos elementos que espera e a extensão pela qual cada um desses elementos atende aos vários padrões e critérios de qualidade esperados. Ao avaliar um serviço o cliente é influenciado pelo habito e por suas expectativas. Quando o pacote de serviços não contém o que o cliente espera por promessas ou experiências anteriores ele irá reclamar (NORMANN, 1993).

Os serviços são artefatos complexos e híbridos; estão permeados com as atividades humanas, com a rede de relacionamentos entre pessoas, e eles não podem ser reduzidos a simplicidade de entidades mecânicas. Como a maioria das entidades complexas são dificilmente projetáveis, no entanto, por essa razão de parecerem não projetáveis, é útil e necessário que se desenvolva uma nova cultura e pratica de design orientado para o serviço (MERONI; SANGIORGI, 2011).

\section{Design de Serviços}

Dada a natureza complexa e evolutiva do Design de Serviço não é simples dar uma definição (HAN, 2010). A autora relata que para muitos designers que trabalham na área, o Design de serviços é sobre o uso de ferramentas, métodos e abordagens para balancear diferentes necessidades dos stakeholders e ajudar a entregar o design de um sistema ou partes do sistema. Para os pesquisadores, ele promove oportunidades excitantes para estudar conhecimentos e habilidades de design que poderiam ser usadas para solucionar problemas em novos contextos e em novos níveis - ambos prático e teórico.

Segundo o Conselho de Tecnologia e Estratégia e o Conselho de Design do Reino Unido (Technology Strategy Board, Design Council) (2014), o Design de Serviços é o processo de criar os pontos de contato (touchpoints) e definir como eles intera- 
gem entre si e o usuário. Para projetar serviços é importante ter os usuários internos e externos em mente. $\mathrm{O}$ uso de ferramentas de design e métodos pode entregar um conhecimento profundo do comportamento do usuário, seus gostos e necessidades, que podem possibilitar novas soluções a serem desenvolvidas. Design de serviço pode ser usado para reprojeto de um serviço existente para melhorar seu funcionamento para os usuários, ou pode ser usado para criar serviços completamente novos. Meroni e Sangiorgi (2011) ressaltam que é importante que uma abordagem holística a todos os aspectos do design seja adotado, e que quando mudando ou alterando qualquer um dos elementos individuais do design todos outros aspectos sejam considerados.

Design de serviços é um campo onde as estratégias estão direcionadas para os usuários e os conceitos são projetados para fazer os serviços funcionarem melhor para as empresas e seus clientes. Oferece uma vantagem competitiva para as empresas garantindo experiências de qualidade para os clientes (MORITZ, 2005).

Pode parecer simples estudar como as pessoas experienciam um serviço, determinar quais partes da entrega não estão unidos e fazê-los todos ter um bom desempenho juntos. Algumas das melhores organizações do mundo lutam para projetar boas experiências de serviço (POLAINE; LOVLIE; REASON, 2013).

Para as empresas de serviço de design oferece a possibilidade para criar valor adicional, para diferenciar dos competidores, para melhor uso de recursos e conectar com o consumidor de forma desejável. Para clientes, design de serviços representa a melhoria da vida diária e prestar experiências de qualidade. $O$ design de serviços conecta os desejos do cliente com os da empresa, atuando como um mediador que entende como construir uma ponte entre os dois num contexto global (MORITZ, 2005).

De encontro com o citado pelos autores, percebe-se o encontro com a Gestão de Design. Segundo Mozota, Klöpsch e Costa (2011) a gestão do design é a implementação do design como um programa formal de atividades dentro de uma corporação por meio da comunicação da relevância do design para as metas corporativas de longo prazo e da coordenação dos resultados de design em todos os níveis da atividade corporativa para atingir os seus objetivos. A característica diferenciadora da gestão do design é seu papel na identificação de maneiras pelas quais o design pode contribuir para o valor estratégico de uma empresa. Também envolve o desdobramento do design dentro da empresa para auxiliá-la a desenvolver sua estratégia; envolvendo o gerenciamento da integração do design na estrutura corporativa no nível operacional (o projeto), no nível organizacional (o departamento) e no nível estratégico (a missão).

\section{Processo de desenvolvimento de serviços}

O Design de serviços cria e formula a interface do cliente e constrói todos os detalhes da jornada de serviço. Métodos e ferramentas são usados para fazer a experiência do serviço consistente, desejável, usável, viável, alinhada com a marca e comercialmente de sucesso (MORITZ, 2005).

A elaboração de um sistema de prestação de serviços é um processo criativo. Inicia-se com um conceito e com uma estratégia para a prestação de um serviço 
que apresente características que possam o diferenciar da concorrência. $O$ projeto de um sistema de serviços envolve aspectos como localização, projeto e layout de instalações que proporcionem um fluxo de trabalhadores e clientes, procedimentos e definições das tarefas para os prestadores dos serviços, medidas para assegurar a qualidade, extensão do envolvimento dos clientes, seleção dos equipamentos e capacidade adequada de serviço (FITZSIMMONS, FITZSIMMONS 2005).

Segundo o Design Council e Technology Strategy Board do Reino Unido (2014) e Moritz (2005), o design de serviços objetiva fazer os serviços usáveis, fáceis e desejados. Moritz (2005) coloca que o design de serviço é um processo que passa pelos quatro D's: descobrir (Discover), definir (Define), desenvolvimento (Develop) e entrega (Deliver). O Design Concil desenvolveu o modelo de design de serviços chamado de Double Diamond (duplo diamante). Esse modelo é composto pelos quatro D's; ele mapeia como o processo de design passa por pontos onde pensamento e as possibilidades são mais amplas o possível até chegar-se as situações em que são deliberadamente reduzidos e focados em objetivos distintos. A Figura 3.1 mostra o modelo com os objetivos de cada fase e quais as ferramentas e métodos indicados em cada uma das fases.

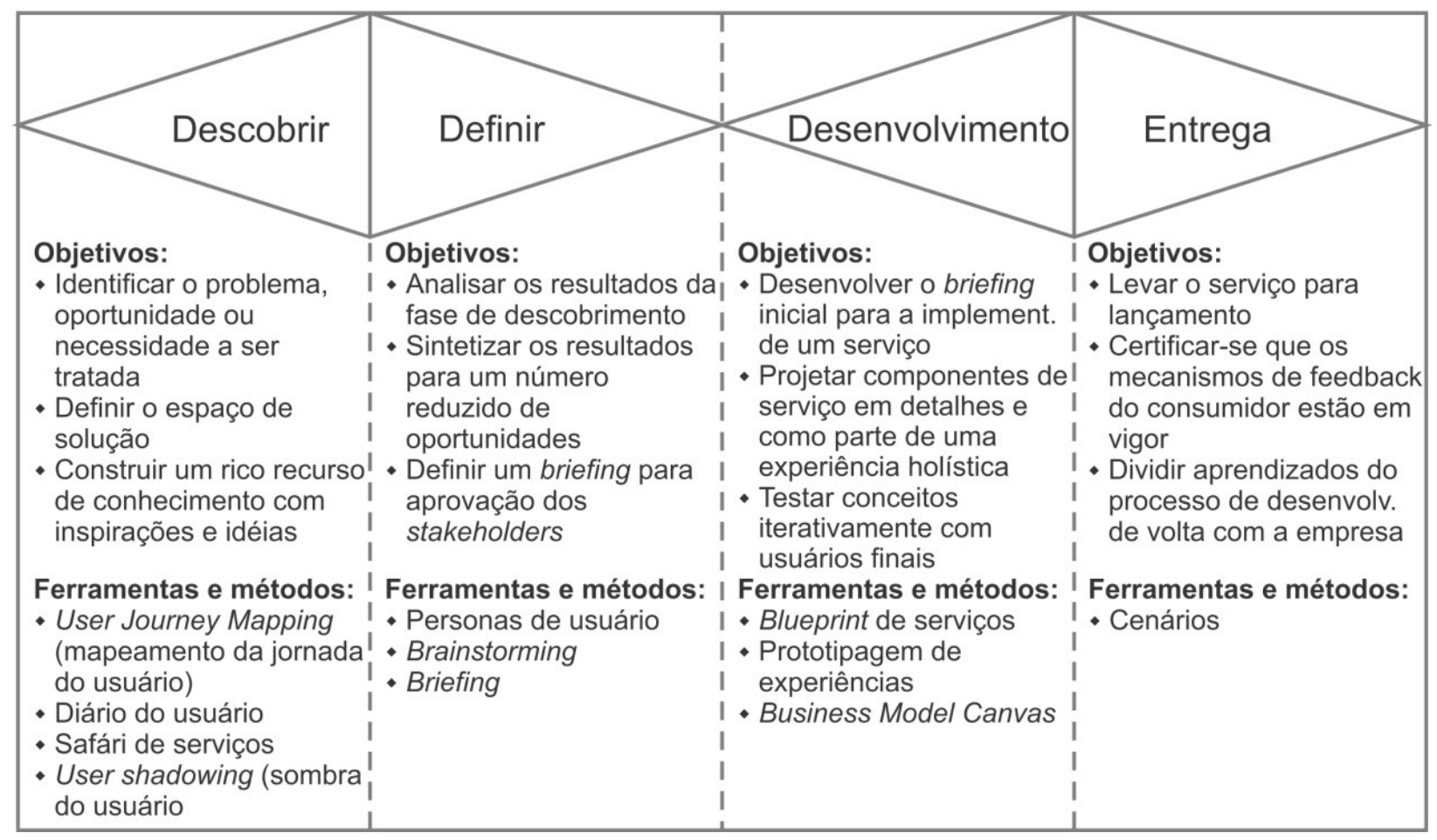

Figura 3.1 - Modelo Double Diamond

Fonte: Elaborado pela autora com base nos dados de Technology Strategy Bord, Design Council (2014).

Existem muitas ferramentas utilizadas no Design de serviços além das sugeridas na Figura 3.1, cada um deles apresentam uma finalidade, as apresentadas no modelo tem suas características condizentes com a fase de aplicação. Essas ferramentas não são de uso exclusivo do Design de serviços, muitas delas são utilizadas em diversas disciplinas que envolvem criação e projetos.

Esses métodos não são protocolos rígidos para serem seguidos impensadamente, mas estruturas que podem e devem ser adaptadas para a tarefa em processo. Al- 
gumas das ferramentas desempenham melhor num pensamento de "quadro maior" enquanto outros focam em detalhes específicos de projeto. Balancear e ligar os dois é importante para obter o melhor resultado (TECHNOLOGY STRATEGY BOARD; DESIGN COUNCIL, 2014).

Polaine, Lovlie e Reason (2013) propõe o design de serviços a partir de insights (a capacidade de ganhar uma compreensão intuitiva precisa e profunda de uma pessoa ou coisa). Como o design de serviços trata de pessoas e seus relacionamentos, então é necessário entender o que os faz se comportar de certa forma. O método de pesquisa de insights em serviços se baseia na etnografia, sociologia, e design centrado no usuário e também métodos específicos do design de serviços. Dentre os métodos utilizados na coleta de dados da pesquisa os autores citam: entrevistas de profundidade, observação do participante - shadowing, participação - se tornando o usuário, safari de serviços, workshop de usuários; esses métodos podem ser facilitados com o uso de algumas ferramentas do design de serviço, como por exemplo a jornada do usuário, diários, etc. Esse tipo de pesquisa pode envolver uma curva de aprendizado, mas geralmente é muito cativante.

Ainda segundo os autores, serviços envolvem diferentes canais de pontos de contato e se desdobram ao longo do tempo, para trabalhar através do design de serviços, é necessária uma forma de mapear visualmente essa complexidade. Blueprint de serviços auxilia a estruturar, projetar, e alinhar as interações dos pontos de contato enquanto elas se desdobram ao longo do tempo. A principal atividade do design de serviços é alinhar o que as pessoas desejam dos pontos de contato que experienciam na interação com o prestador de serviço (linha de frente) com os processos de negócio que dão suporte a essas atividades (back-stage).

Coletar insights para suprir o design de serviços é bom, mas o serviço também precisa ter uma ideia de negócios por trás, sem isso, as ideias não serão economicamente viáveis e sustentáveis. A chave para a proposta de negócio de serviço é conseguir responder a três questões: as pessoas entendem o que o novo serviço faz? As pessoas veem valor disso nas suas vidas? As pessoas entendem com usar? Pegando pedaços e jornadas da blueprint de serviço é possível explorar se um ponto de contato se comunica adequadamente e comunica as respostas para essas perguntas sob a perspectiva do usuário do serviço. Pode-se, então, desenvolver cada ponto de contato na blueprint em uma especificação detalhada de projeto para a criação de um ponto de contato (POLAINE; LOVLIE; REASON, 2013).

Segundo Morelli (2009) o resultado de um processo de desenvolvimento de um serviço nunca é perfeitamente definido, mas deveria ser um sistema de componentes (ou módulos) que podem ser unidos em configurações diferentes. Uma estrutura aberta, ou plataforma modular, permitiria que os envolvidos no serviço escolherem a solução mais adequada e para desenvolver a configuração de serviço mais apropriada. Nessa abordagem métodos e ferramentas que são familiares a projetistas podem ser utilizadas, mas novas técnicas também podem ser adaptadas de outros contextos disciplinares.

\section{Experiência do Usuário (UX) e Projeto Centrado no Usuário}


A experiência do usuário é encontrada como elemento da norma ISO 924111:2010 - Projeto centrado no ser humano para sistemas interativos. Segundo essa norma, o projeto centrado no ser humano é uma abordagem para o desenvolvimento de sistemas interativos que objetiva tornar os sistemas utilizáveis e úteis, dando ênfase aos usuários, suas necessidades e exigências, pela aplicação de conhecimentos e as técnicas de usabilidade e fatores humanos/ergonomia. Esta abordagem aumenta a eficácia e a eficiência, aprimora o bem-estar do ser humano, a satisfação do usuário, a acessibilidade e a sustentabilidade; e neutraliza possíveis efeitos adversos do seu uso na saúde, na segurança e no desempenho (ABNT, 2011).

Nesse contexto, como foi apresentado anteriormente, a experiência do usuário é definida como as percepções e respostas das pessoas, resultantes do uso e/ou uso antecipado de um produto, sistema ou serviço. A experiência do usuário é uma consequência da imagem da marca, da apresentação, da funcionalidade, do desempenho do sistema, do comportamento interativo e das capacidades assistivas do sistema interativo, dos estados interno e físico do usuário, resultantes de experiências anteriores, atitudes, habilidades e personalidade, e do contexto de uso. (ABNT, 2011).

Tullis e Albert (2008) expõem que alguns autores diferenciam os termos usabilidade e experiência do usuário. A usabilidade geralmente é considerada como a habilidade de um usuário usar o objeto para realizar a tarefa com sucesso, enquanto a experiência do usuário tem uma abordagem mais ampla, analisando toda a interação do indivíduo com o objeto, assim como pensamentos, sentimentos, e percepções que resultam da interação.

Park et al. (2013) em seu estudo em que buscou desenvolver definições de UX e identificar os fatores que podem influencia-la diretamente, coloca que UX pode ser definida como uma experiência global que consiste em todos os aspectos da interação dos usuários com um produto ou serviço. A UX se dirige a experiência que ocorre quando um usuário interage com um produto ou serviço. Segundo os autores muitos pesquisadores e profissionais concordam que UX inclui todos aspectos da interação do usuário, mas experiências sem o produto ou serviço devem ser excluídas. Nesse estudo é definido como os principais elementos da UX como a usabilidade, o efeito, e o valor do usuário e seus sub-elementos.

Pucillo e Cascini (2014) defendem que uma experiência não pode ser projetada nem garantida: ela pode apenas ser oferecidas. Produtos devem então permitir o experiencial para os usuários, para não apenas provocar o prazer quando os usuários estão no modo de uso adequado, mas também para evitar a frustração no caso de os usuários simplesmente precisam cumprir uma tarefa básica.

\section{Projeto Centrado no Usuário}

A Experiência do Usuário (UX) faz parte do Design Centrado no Usuário e seus princípios, geralmente a UX é mais relacionada a avaliação da experiência, mas podese ter melhores resultados tendo uma preocupação com esses fatores na etapa de projeto, nesse caso seguindo o método de projeto centrado no usuário. Nessa seção será apresentado o projeto centrado no usuário tendo como referencia a NBR ISO 9241-11:2010. 
A utilização de uma abordagem centrada no ser humano ${ }^{2}$ para projeto e desenvolvimento produz benefícios econômicos e sociais substanciais para os usuários, empregadores e fornecedores. Fazendo-se uso de métodos centrados no ser humano adequados pode-se reduzir o risco do produto falhar no atendimento aos requisitos dos stakeholders ou de ser rejeitado por seus usuários. Segundo a norma, uma abordagem centrada no ser humano deve seguir os princípios: o projeto é baseado em um entendimento explícito de usuários, tarefas e ambientes; os usuários são envolvidos em todo o projeto e desenvolvimento, o projeto é conduzido e refinado por uma avaliação centrada no usuário; o processo é iterativo; o projeto aborda a experiência do usuário como um todo; a equipe de projeto inclui competências e perspectivas multidisciplinares.

Com a identificação da necessidade de se desenvolver um sistema, produto ou serviço quatro atividades de projeto centrado no ser humano são recomendadas estarem presentes durante o projeto de qualquer sistema interativo: compreender e especificar o contexto de uso; especificar os requisitos do usuário; produzir soluções de projeto; avaliar o projeto. A Figura 4.1 ilustra a interdependência entre as atividades de projeto centrado no ser humano. Ela não indica um processo linear, mas ao contrário, ilustra que cada atividade de projeto centrada no ser humano utiliza resultados de outras atividades.

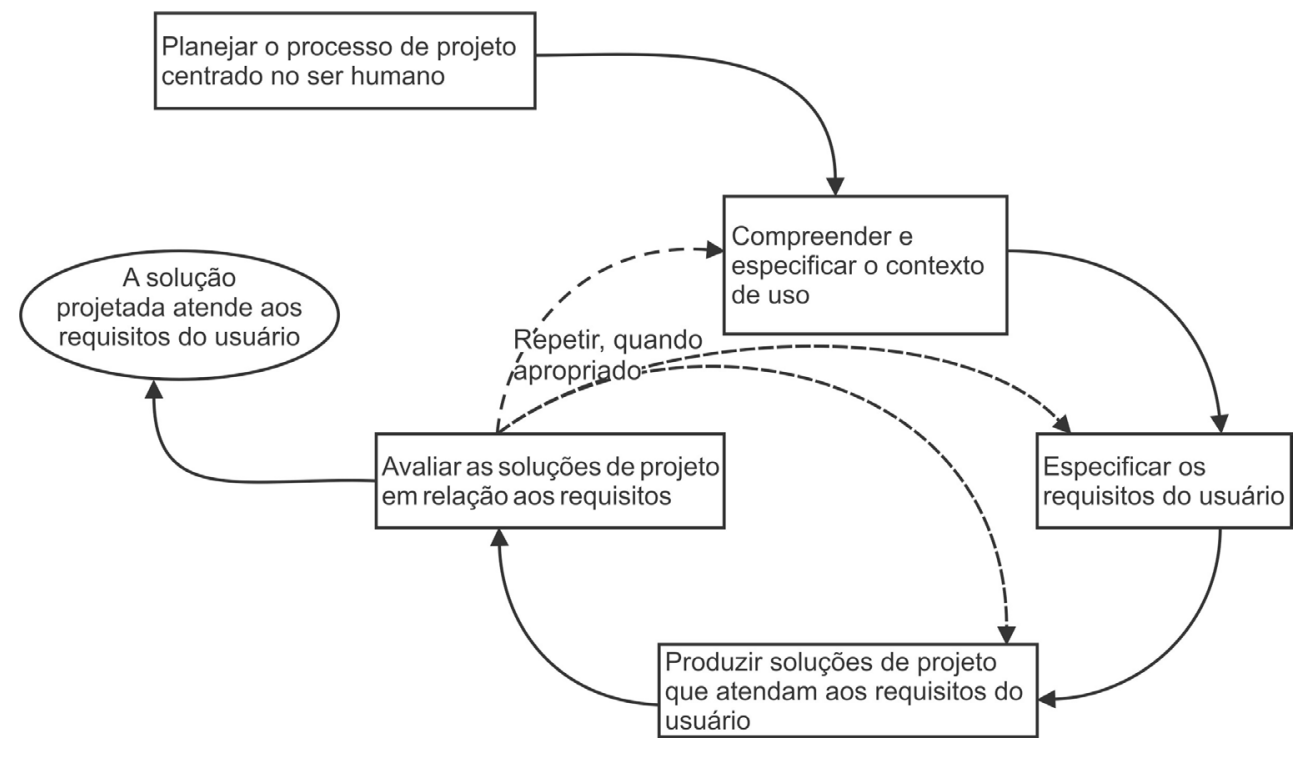

Figura 3.2 - Interdependência entre as atividades de projeto centrado no ser humano Fonte: NBR ISO 9241-11:2010, Projeto centrado no ser humano para sistemas interativos, (ABNT, 2011, p. 14).

$\mathrm{Na}$ atividade de compreender e especificar o contexto de uso as características dos usuários, das tarefas e dos ambientes organizacionais, técnico e físico definem o contexto no qual o sistema é utilizado. É importante coletar e analisar a informação sobre o contexto atual, objetivando compreender e especificar o contexto que será aplicado ao futuro sistema. A análise de sistemas existentes ou similares pode fornecer informações sobre questões do contexto, incluindo deficiências e níveis de referência de performance e satisfação.

20 termo "projeto centrado no ser humano" é utilizado em vez de "projeto centrado no usuário" buscando enfatizar que a ABNT NBR ISO 9241 também trata dos impactos nos demais stakeholders, e não apenas aqueles tipicamente considerados como usuários. Entretanto, na prática, esses termos são frequentemente usados como sinônimos (ABNT, 2011, p.5). 
Esta análise pode revelar necessidades, problemas e restrições que poderiam de outra forma passar despercebidos, mas que precisam ser abordados pelo futuro sistema. A descrição do contexto de uso deve incluir os usuários, e demais grupo de stakeholders, as características dos usuários, os objetivos e as tarefas dos usuários, o ambiente do sistema.

$\mathrm{Na}$ etapa de identificar os requisitos dos usuários, deve-se identificar as necessidades e especificar requisitos funcionais e demais requisitos para o produto ou sistema. Essa é uma atividade que deve ser ampliada para criar uma declaração explícita dos requisitos do usuário em relação ao contexto de uso pretendido e aos objetivos de negócio do sistema. Dependendo do escopo do sistema, os requisitos do usuário podem incluir requisitos para mudanças organizacionais e revisões de estilo de trabalho e podem sugerir oportunidades de combinar produtos e serviços.

A fase de produzir soluções de projeto se tem uma ligação direta com a UX, decisões de projeto têm um impacto importante na experiência do usuário. O projeto centrado no ser humano pretende alcançar uma boa experiência do usuário considerando esta experiência durante todo o processo de projeto. Possíveis soluções de projeto são feitas com base na descrição do contexto de uso, nos resultados de avaliações iniciais, no estado da arte estabelecido, nas orientações e normas de projeto e usabilidade, bem como na experiência e conhecimento da equipe multidisciplinar de projeto. Outros requisitos de usuário que vierem a surgir como potenciais soluções de projeto são detalhados e avaliados. A produção de soluções de projeto deve projetar as tarefas do usuário, tornar as soluções de projeto mais concretas, alterar as soluções de projeto em resposta a uma avaliação centrada no usuário e feedback, comunicar as soluções de projeto para os responsáveis por sua execução.

A atividade final de avaliação do projeto é sugerida que seja realizada mesmo nas primeiras fases do projeto. Recomenda-se que os conceitos de projeto sejam avaliados para se obter um melhor entendimento das necessidades dos usuários. $A$ utilização de um produto/serviço/sistema na vida real é complexo, e mesmo que as orientações de projeto ergonômico possam dar um apoio útil aos designers, a avaliação centrada no usuário é um elemento essencial para o projeto centrado no ser humano. A avaliação pelos usuários nem sempre é prática ou de boa relação custo-benefício em todas as fases do projeto. Em tais circunstâncias é recomendado que as soluções de projeto também sejam avaliadas de outras maneiras - utilizando modelagem de tarefa e simulações. Estes métodos ainda são centrados em qual será a experiência do usuário no uso do sistema, mesmo que os próprios usuários não participem diretamente.

\section{Medidas de UX}

Existem muitos kits de ferramentas para efetuar avaliações tradicionais de usabilidade, mas a avaliação da UX se diferencia bastante da usabilidade. Medidas objetivas como tempo de execução da tarefa ou número de erros não são confiáveis para a UX, mas é preciso saber como o usuário sente sobre o sistema. A avaliação de UX não pode ser conduzida apenas pela observação do usuário completar uma tarefa em um teste de laboratório (OBRIST, ROTO, VÄÄNÄNEN-VAINIO-MATTILA, 2009). 
Já Vermeeren, et al. (2010) colocam que a relação entre usabilidade e UX está entrelaçada. Algumas tentativas têm sido tomadas para demarcar ou mesmo descartar a fronteira entre eles, conceitualmente e operacionalmente. Os autores assumem a posição de que a usabilidade é incluído na UX. A implicação é que a avaliação UX acarreta no aumento dos métodos existentes para avaliação de usabilidade.

A avaliação de UX busca métodos de avaliação que forneçam informações sobre como o usuário se sente sobre usar o sistema (produto ou serviço) projetado. Esse é um requerimento comum para todos os métodos de avaliação de UX, mas pode haver diferentes tipos de métodos projetados para diferentes casos (OBRIST, ROTO, VÄÄNÄNEN-VAINIO-MATTILA, 2009).

O campo da UX tem uma alta gama de métodos de pesquisa disponível. Os projetos tendem a ser beneficiados se usarem alguns métodos de pesquisa (coleta de dados e mensuração). Infelizmente, muitas equipes de projeto usam apenas um ou dois métodos que tem familiaridade. A questão chave é o que fazer e quando. Para entender quando usar qual método, é útil visualizar ao longo de uma estrutura de 3 dimensões com os eixos: atitudinal $\mathrm{X}$ comportamental, qualitativo $\mathrm{X}$ quantitativo, e contexto de uso. A Figura 3.3 ilustra onde vinte métodos populares se encontram nessas dimensões.

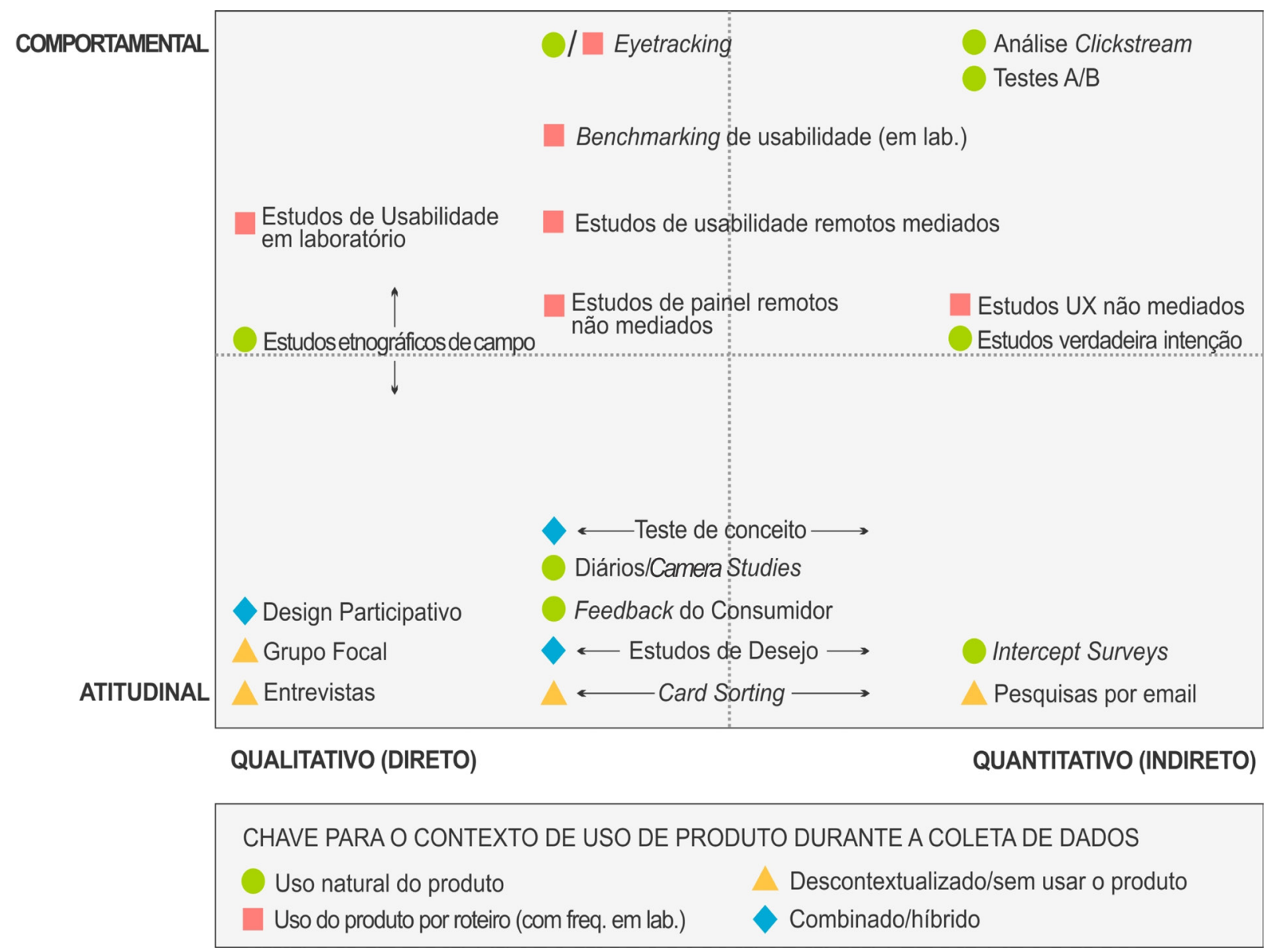

Figura 3.3 - Panorama dos métodos de pesquisa do usuário Fonte: Adaptado de Rohrer 2014.

Pelo panorama pode-se observar que os métodos se distribuem igualmente entre as medidas de atitudes e comportamento, em sua maioria os métodos estão entre 
as medidas quantitativas e qualitativas, e sua maioria são de contexto do uso natural do produto/serviço. Segundo o autor cada dimensão fornece uma maneira de distinguir entre estudos em termos das perguntas que respondem e o propósito que eles são mais adequados.

\section{Desenvolvimento}

Com os conteúdos levantados na revisão bibliográfica foi montada uma tabela com as características fundamentais do Design de Serviço e UX (Tabela 5.1).

\begin{tabular}{|c|c|}
\hline Design de Serviços & Experiência do Usuário \\
\hline Foco nos usuários & $\begin{array}{l}\text { Projeto baseado em entendimento dos } \\
\text { usuários, tarefas eambientes; usuários são en- } \\
\text { volvidos em todo o desenvolvimento, conduzido } \\
\text { por avaliação centrada no usuário; o processo é } \\
\text { interativo; aborda a experiência como um todo; } \\
\text { equipe multidisciplinares }\end{array}$ \\
\hline $\begin{array}{c}\text { Cria e formula a interface com o cliente; } \\
\text { parte de um conceito e estratégia; se baseia na } \\
\text { etnografia, sociologia, e design centrado no } \\
\text { usuário }\end{array}$ & $\begin{array}{l}\text { Definida pelas percepções e respostas das } \\
\text { pessoas resultantes do uso }\end{array}$ \\
\hline $\begin{array}{c}\text { Objetiva fazer os serviços usáveis, fáceis e } \\
\text { desejados }\end{array}$ & $\begin{array}{l}\text { Objetiva sistemas utilizáveis e úteis, ênfase } \\
\text { aos usuários - necessidades e exigências }\end{array}$ \\
\hline $\begin{array}{l}\text { Métodos e ferramentas - conhecimento } \\
\text { do usuário - entrevistas de profundidade, obser- } \\
\text { vação do participante }\end{array}$ & $\begin{array}{l}\text { Métodos e ferramentas: atitudinal X com- } \\
\text { portamental, qualitativo } x \text { quantitativo, e con- } \\
\text { texto de uso }\end{array}$ \\
\hline $\begin{array}{l}\text { Metodologia projeto: 4D's - descobrir, } \\
\text { definir, desenvolver, entregar }\end{array}$ & $\begin{array}{l}\text { Design Centrado no Usuário (DCU) - } 4 \\
\text { atividades }\end{array}$ \\
\hline $\begin{array}{l}\text { Descobrir - identificar problema, definir } \\
\text { espaço de solução, construir conhecimento e } \\
\text { inspirações e ideias }\end{array}$ & $\begin{array}{l}\text { Compreender e especificar o contexto de } \\
\text { uso: descrição do contexto de uso deve incluir } \\
\text { os usuários, as características dos usuários, os } \\
\text { objetivos e as tarefas dos usuários, o ambiente } \\
\text { do sistema. }\end{array}$ \\
\hline $\begin{array}{l}\text { Definir - analisar dados, identificar oportu- } \\
\text { nidades, definir briefing }\end{array}$ & $\begin{array}{l}\text { Especificar os requisitos do usuário: iden- } \\
\text { tificar as necessidades e especificar requisitos } \\
\text { funcionais e demais requisitos }\end{array}$ \\
\hline $\begin{array}{l}\text { Desenvolver - projetar componentes de } \\
\text { serviço, testar conceitos }\end{array}$ & $\begin{array}{l}\text { Possíveis soluções: com base na descrição } \\
\text { do contexto de uso, resultados de avaliações } \\
\text { iniciais, orientações e normas de usabilidade }\end{array}$ \\
\hline $\begin{array}{l}\text { Entregar - lançamento, certificar o funcio- } \\
\text { namento, dividir aprendizado. }\end{array}$ & $\begin{array}{l}\text { Avaliar projeto: conceitos aliados para se } \\
\text { obter um melhor entendimento das necessida- } \\
\text { des dos usuários }\end{array}$ \\
\hline
\end{tabular}

Tabela 5.1 - Tabela de características Design de Serviços e UX.

Fonte: elaborado pelos autores.

O Design de serviços tem suas atividades e desenvolvimento com foco no usuário, é ele que cria as interações entre o usuário e empresa e que projeta a experiência de serviço que engloba a entrega de valor para os clientes/usuários. O objetivo é fazer serviços usáveis, fáceis e desejados. Durante o desenvolvimento de serviços o design utiliza ferramentas que sejam condizentes com a etapa de projeto, essas são usadas 
para se ter maior conhecimento do usuário, para identificar as necessidades e oportunidades e também reforçando o usuário como parte central do projeto. O método de desenvolvimento de serviços consiste em quatro fases que abrangem o descobrir, definir, desenvolvimento e entrega.

A Experiência do Usuário (UX) é as percepções e respostas do usuário resultante da interação com o serviço ou produto. Em termos de projeto a UX está ligada ao projeto centrado no usuário na literatura de Fatores Humanos. No projeto/design centrado no usuário, o usuário é o personagem central em todo projeto e a experiência é abordada como um todo. Objetiva serviços utilizáveis e úteis com ênfase nas necessidades e exigências dos usuários. A UX faz uso de métodos e ferramentas para a coleta de dados e mensurar a experiência, essas podem ter objetivos relacionados ao comportamento ou atitude, serem qualitativas e/ou quantitativas, relacionadas ao contexto de uso. O Projeto centrado no usuário trabalha com quatro atividades - compreender e especificar o contexto de uso, especificar os requisitos do usuário, possíveis soluções e avaliar o projeto.

Pode-se perceber muitas similaridades entre as características descritas nesses últimos dois parágrafos. Essas similaridades podem se dar pela importância do usuário nessas duas áreas.

\section{Conclusão}

Esse artigo partiu da crescente participação dos serviços na economia mundial, e a necessidade das empresas de melhorar seu relacionamento com os clientes. As empresas buscam entregar experiências de serviço e valor que satisfaça os clientes buscando a melhoria na relação entre eles, assim criando fidelidade e valorização da marca. Esse relacionamento pode ser aprimorado ou atingido pelo uso da experiência do usuário (UX) em conjunto com o design de serviços.

Esse trabalho buscou identificar as interseções entre essas áreas do conhecimento, após uma revisão narrativa da literatura foi realizada uma análise comparativa desses assuntos. As interseções identificadas na tabela comparativa são apresentadas na Figura 5.1.

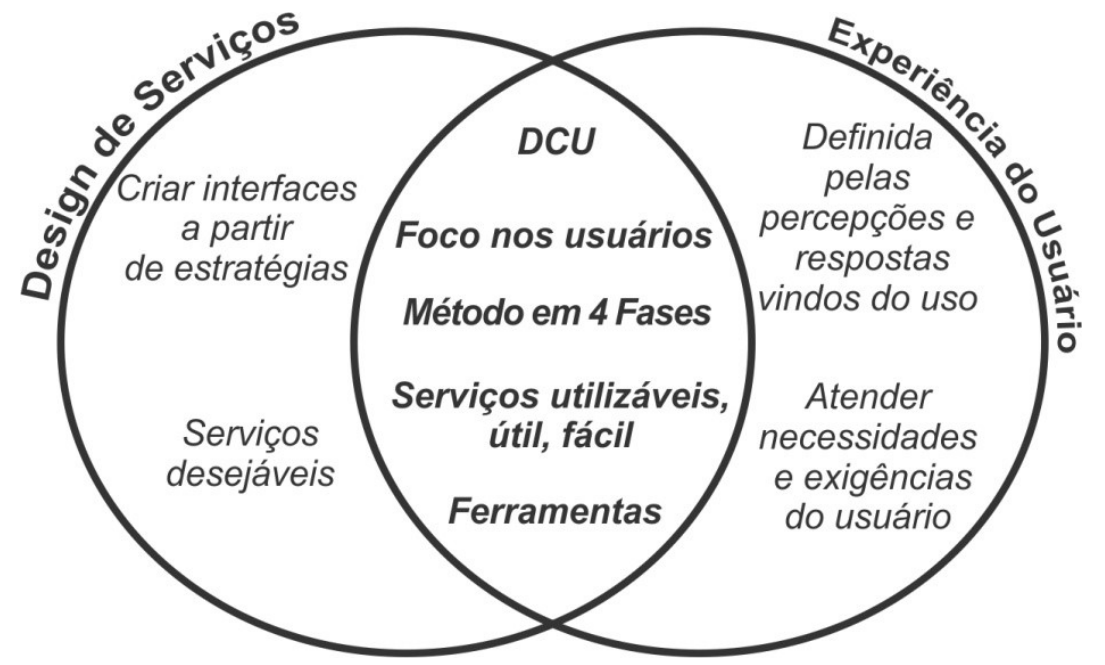

Figura 5.1 - Interseções identificadas entre Design de Serviços e Experiência do Usuário. Fonte: Elaborado pelos autores. 
Pôde-se perceber que tanto o Design de serviço quanto a Experiência do Usuário têm o usuário como diretriz e seus objetivos estão diretamente alinhados. Quanto aos métodos e ferramentas, Polaine, Lovlie e Reason (2013) colocam que o processo de coleta do Design de Serviços extrai de várias metodologias de pesquisa, dentre eles usabilidade, UX e Design Centrado no Usuário. Assim, as áreas acabam por utilizar alguns métodos e ferramentas iguais.

As metodologias de projeto de ambas as áreas têm o projeto dividido em quatro etapas e, como se percebe na Tabela 5.1, cada uma dessas fases que compõe essas metodologias apresentam objetivos muito próximos, o que mais diferencia é a abordagem quanto esses objetivos. O projeto centrado no usuário tem foco nas questões ergonômicas, de usabilidade e UX enquanto o Design de Serviços tem um abordagem mais holística do serviço. Isso pode-se explicar pelo fato do design ser uma disciplina com foco no usuário e seus projetos seguem os princípios do Design/projeto centrado no usuário. Polaine, Lovlie e Reason (2013) expõe que o design de serviços pode ser rastreado ao tradicional design industrial, sendo que no século XX a profissão de design contribuiu para a melhoria do padrão de vida, e a geração de 1920 se esforçou para humanizar a tecnologia, hoje, se percebe essa continuidade com o design atuando nos serviços.

Assim, conclui-se que as áreas de Design de Serviço e Experiência do Usuário apresentam vários relacionamentos, o que facilita o trabalho em conjunto desses fatores. Trabalhando de forma conjunta os serviços desenvolvidos provavelmente terão uma boa avaliação perante os usuários, trazendo benefícios as empresa prestadora de serviço. Outro fator que enfatiza o relacionamento entre esses campos é que o Design de serviços cria um serviço que irá gerar sempre uma experiência no usuário.

\section{Referências Bibliográficas}

Associação Brasileira de Normas Técnicas (ABNT). NBR ISO 9241-11:2010 Ergonomia da interação humano-sistema - Parte 210: Projeto centrado no ser humano para sistemas interativos. 2011.

CORDEIRO, Alexander Magno et al. Revisão sistemática: uma revisão narrativa. Revista do Colégio Brasileiro de Cirurgiões, Rio de Janeiro, v. 34, n. 5, p. 428-431, nov./ dez., 2007.

FERREIRA, G. S. Indústria perde espaço e serviços já são quase 70\% do PIB. Radar econômico. Disponível em: http://blogs.estadao.com.br/radar-economico/2014/02/27/ industria-perde-espaco-e-servicos-ja-sao-quase-70-do-pib/ Acessado em: 29/08/2014.

FITZSIMMONS, James A.; FITZSIMMONS, Mona J.. Administração de serviços: operações, estratégia e tecnologia de informação. 4. ed. Porto Alegre: Bookman, 2005.

HAN, Q. Practices and Principles in Service Design: Stakeholder, Knowledge and Community of Service. Dundee:University of Dundee, 2010. 
Instituto Brasileiro de Geografia e Estatística (IBGE). Pesquisa anual de serviços 2011. Rio de Janeiro, 2013.

MERONI, A.; SANGIORGI, D. Design for services. Farnham: Gower, 2011.

MORELLI, N. Service as value co-production: reframing the service design process. Journal of Manufacturing Technology Management, v. 20, n. 5, p. 568-590, 2009.

MORITZ, Stefan. Service Design: practical access to an evolving field. 2005. $245 \mathrm{f}$. Dissertação (Mestrado) - Curso de European Studies In Design, KISD, Londres, 2005. Disponível em: http://stefan-moritz.com/_files/Practical Access to Service Design. pdf. Acesso em: 10 mar. 2015.

MOZOTA, B. B.; KLÖPSCH, C.; COSTA, F. C. X. Gestão do design: usando o design para construir valor de marca e inovação corporativa. Porto Alegre: Bookman, 2011.

NORMANN, Richard. Administração de serviços: estratégia e liderança na empresa de serviços. São Paulo: Atlas, 1993.

NORMANN, R.; RAMIREZ, R. Designing interactive Strategy: From value chain to value constellation. New York: John Wiley and Sons, 1998.

OBRIST M, ROTO V, VÄÄNÄNEN-VAINIO-MATTILA K. User Experience Evaluation Do You Know Which Method to Use? CHI 2009 - Conference of Human Factors and Computer Systems. p. 2763 - 2766, 2009.

PARK, J. et al. Developing elements of user experience for mobile phones and services: survey, interview, and observation approaches. Human Factors Manufacturing \& Service Industries, v. 23, n. 4, p. 279-293, 2013.

POLAINE, A.; LØVLIE, L.; REASON, B. Service Design: From Insight to Implementation. New York: Rosenfeld Media, 2013.

PUCILLO, F.; CASCINI, G. A framework for user experience, needs and affordances. Design Studies, v. 35, n. 2, p. 160-179, mar. 2014.

ROHRER, C. When to use which user-experience research methods. Nielsen Norman Group, 12 outubro de 2014. Disponível em: http://www.nngroup.com/articles/which -ux-research-methods/. Acessado em: 09/05/15.

RUDD, C.; LLOYD, V. Service Design. London: The Stationery Office, 2007.

TECHNOLOGY STRATEGY BOARD; DESIGN COUNCIL. Design methods for developing services : an introduction to service design and a selection of service design tools. Disponível em: https://www.innovateuk.org/documents/1524978/1814792/ 
Keeping+Connected+-+Design+methods+for+developing+services $+\% 2528$ Archive\%2529/d358586d-80b3-4f1e-b753-16750434829d. Acessado em: 23/08/2014.

TULLIS, Tom; ALBERT, Bill. Measuring the user experience: collecting, analyzing, and presenting usability metrics. Boston, MA: Morgan Kaufmann, 2008.

User Experience Professionals Association (UXPA). About UX. Disponivel em: https:// uxpa.org/resources/about-ux. Acessado em: 01/09/2014.

VERMEEREN, A. P. O. S. et al. User experience evaluation methods: current state and development needs. Proceedings: NordiCHI 2010, p. 521-530, 2010. 